\title{
The impact of helmet use on oral and maxillofacial injuries associated with electric-powered bikes or powered scooter: a retrospective cross-sectional study
}

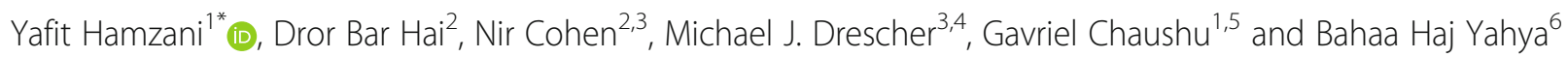

\begin{abstract}
Background: Electric bikes (E-bikes) and powered scooters (P-scooters) have become increasingly popular modes of public transportation, but they have been associated with injuries of all kinds, including dental trauma. Helmet use is promoted as a means of reducing injuries in accidents involving motorized and unmotorized vehicles. The aim of the study was to evaluate the impact of helmet use on the number and severity of oral and maxillofacial injuries caused by E-bikes and P-scooters.
\end{abstract}

Methods: A retrospective cross-sectional study design was used. The cohort included all patients referred to the emergency department of a tertiary medical center in 2014-2020 with oral and maxillofacial injuries involving Ebikes or P-scooters. Data were collected from the medical files on demographics, types of injuries, circumstances of occurrence, work-up, treatment, and outcome. Use of a helmet was recorded in each case.

Results: Of the total 1417 patients referred to the emergency department for E-bike and P-scooter-related trauma, 62 had oral and maxillofacial injuries, including 57 riders and 5 pedestrians. All had hard- or soft-tissue injuries; 20 (32.2\%) had head injuries and 22 (35.5\%) had dentoalveolar injuries. Eleven riders had worn a helmet at the time of injury (17.7\%). Helmet use was associated with time of injury (weekday/weekend, daytime/night-time), type of motorized vehicle (E-bike or P-scooter), head injury, and number of bone fractures. Head injuries occurred more often on the weekend (57.9\%) than during the week (20.9\%) and were more likely to occur in riders who were not protected by a helmet (37.3\% vs 18.2\%). Patients who used helmets also had a lower rate of fractured bones (18.2\%) and dentoalveolar injuries (23.7\%) than patients who did not (68.8 and 37.3\%, respectively). Interestingly, helmet use had no protective effect on soft-tissue injuries.

Conclusions: Helmet use by E-bike and P-scooter riders decreased the probability of head injury and of hard tissue and dentoalveolar injuries. These results may provide guidance for effective legislation and regulation of helmet use and improved treatment protocols for general and dental physicians.

Keywords: Emergency department, Craniofacial injury, Maxillofacial injury, electric bikes, Powered scooters, Helmets

\footnotetext{
* Correspondence: yafithm87@gmail.com

'Department of Oral and Maxillofacial Surgery, Rabin Medical Center Beilinson Hospital, 4941492 Petach Tikva, Israel

Full list of author information is available at the end of the article
}

\section{$\triangle B M C$}

(c) The Author(s). 2021 Open Access This article is licensed under a Creative Commons Attribution 4.0 International License, which permits use, sharing, adaptation, distribution and reproduction in any medium or format, as long as you give appropriate credit to the original author(s) and the source, provide a link to the Creative Commons licence, and indicate if changes were made. The images or other third party material in this article are included in the article's Creative Commons licence, unless indicated otherwise in a credit line to the material. If material is not included in the article's Creative Commons licence and your intended use is not permitted by statutory regulation or exceeds the permitted use, you will need to obtain permission directly from the copyright holder. To view a copy of this licence, visit http://creativecommons.org/licenses/by/4.0/ The Creative Commons Public Domain Dedication waiver (http://creativecommons.org/publicdomain/zero/1.0/) applies to the data made available in this article, unless otherwise stated in a credit line to the data. 


\section{Introduction}

Electric bicycles (E-bikes) and powered stand-up scooters (P-scooters) are becoming increasingly popular modes of transportation worldwide [1, 2]. They are convenient, low cost, and easy to use, lessen commute times, and consume less energy than other motorized vehicles [2-4]. However, concerns regarding the risks of injury are growing [2]. E-bikes and Pscooters riders are at high injury risk for high-speed collision with motorized vehicles in comparison to pedestrians and conventional bicyclists. Thus, the formers more likely to be involved in high energy accidents, suffering more severe injuries, and requiring extensive and prolonged medical treatment [1]. In 2000-2017, 133,872 injuries associated with E-bikes and P-scooters were reported to the United States National Electronic Injury Surveillance System [2], with E- bikes more likely than P-scooters to be associated with internal injuries and hospitalization [2]. A study of vehicular trauma in 2014-2019 found that Ebikes and P-scooters were responsible for 378 of the 3686 hospital admissions for dental and maxillofacial injuries (10.3\%) [1]. The authors suggested that helmets may have a protective benefit against oral injuries $[1,2]$, but the data are still sparse. The aim of the present study was to evaluate the effect of helmet use on the number and severity of oral and maxillofacial injuries caused by E-bikes and P-scooters over a 6year period in Israel. The 0- hypothesis was using a helmet protects the rider and reduces number and severity of maxillofacial injuries of all kinds; hard, softtissue and dentoalveolar.

\section{Methods}

A retrospective, cross-sectional study was conducted in the department of oral and maxillofacial surgery of a tertiary medical center from January 2014 to March 2020. The cohort included 1417 patients referred to the emergency department (ED) for injuries involving E-bikes and P-scooters. Of the total patients referred to the ED for E-bike and P-scooter-related trauma, 62 had oral and maxillofacial injuries. Various data were collected from oral and maxillofacial injured patients' medical files:

1) Gender- male/ female

2) Age- in years

3) Alcohol consumption during $4 \mathrm{~h}$ before the injuryyes/no

4) Drug consumption during $4 \mathrm{~h}$ before the injuryyes/no

5) Helmet use - yes/no, "data regarding the type of the helmet were missing.
6) Time of arrival to ED - categorized as day hours (6 am to $6 \mathrm{pm}$ ) or night hours (6 pm to $6 \mathrm{am}$ )

7) Day of arrival to ED - categorized as middle of the week (Sunday till Wednesday) or weekend (Thursday to Saturday)

8) Injured patient - categorized as pedestrian, cyclist, or driving high energy vehicle.

9) Injury vehicle related- E-bike or P-scooter.

10) Self or ambulance evacuation

11) Glasgow Coma Scale (GCS) on presentation

12) Imaging modality- categorized as:

- Computed tomography (CT)

- Magnetic resonance imaging (MRI)

- Plain radiographs

- Ultrasound (US)

- Other modality

- Combined

- None

13) Parts of body injured - face, thorax, back, abdomen and pelvis, upper extremities, or lower extremities.

14) Number of body regions injured- categorized as single or multiple.

15) Head injury- defined as injury to the brain or neurocranium; the latter is formed from the occipital bone, two temporal bones, two parietal bones, the sphenoid, ethmoid and frontal bones; they are all joined together with sutures, surrounds and protects the brain and brainstem.

16) Surgical procedure- done to the specific patient.

17) Fractures- categorized as single or multiple.

18) Bones that were fractured- radius, maxilla, etc.

19) Fracture type - categorized as open or closed.

20) Side injured - categorized as right, left, or both.

21) Hemorrhage- yes/no

22) Bleeding organ

23) Need of blood transfusion - yes/no

24) Lacerations - yes/no

25) Organs that were lacerated- lips, chin, etc.

26) Number of hospital admission days

27) Departments that were responsible for surgery performance- for example oral and maxillofacial surgery, neurosurgery, ophthalmology or orthopedics

28) Treatment by intensive care unit (ICU) - yes/no

29) OMS procedure-no treatment was required, stitching, open reduction and internal fixation, tooth fixation, mandibulo-maxillary fixation or extraction.

30) Dentoalveolar trauma- refer to injuries related to teeth and the structures supporting the teeth: periodontal ligament and alveolar bone; tooth fractures (crown and root), subluxation, alveolar process trauma, tooth avulsion, or prosthetic restoration fracture or loss.

31) No of teeth involved in Dentoalveolar trauma.

32) Anesthesia- categorized as local or general. 
33) Discharge destination- home, rehabilitation center

34) Returns to ED after discharge- up to 3 months after the initial ED visit, yes/no

The main variable was helmet use, which was documented in each case, and findings were compared between riders who wore or did not wear a helmet at the time of injury. The study protocol was approved by the Helsinki Committee of Rabin Medical Center (approval number 0194-20-RMC).

Data analysis was performed with SAS statistical software, version 9.4 (SAS Institute Inc., Cary, NC, USA). Continuous data are summarized as mean and standard deviation, and categorical data as number and percent. Chi-square, Kruskal Wallis and Mann-Whitney tests were used to compare categorical variables between two groups $p<0.05$ was considered statistically significant. Odds ratios (OR) were calculated as well.

\section{Results}

\section{Patient demographics}

A total of 1417 patients were referred to the ED during the study period for injuries caused by E-bikes and Pscooters. Sixty-two (4.4\%) had oral and maxillofacial injuries and formed the study group. They included 41 male $(66.1 \%)$ and 21 female patients of mean age years $32.0 \pm 13.0 ; 46.8 \%$ were $21-30$ years old (Fig. 1 ). There was no significant difference in sex distribution or age between the patients who had oral and maxillofacial injuries and those who did not $(n=1355$, male/female ratio $74 \% / 26 \%$; mean age $31.6 \pm 15.8$ years. Medical background analysis showed that 50 patients (80.6\%) were otherwise healthy. Only $6.5 \%$ of injuries were alcohol-related and none was drug-related.

The annual number of referrals for oral and maxillofacial injuries increased with time concomitant with an increase in general referrals (Fig. 2).

\section{Type of vehicle and helmet use}

An E-bike was involved in 48 cases (77.4\%) and a P-scooter in 14 . In 57 cases (91.9\%), the injured party was riding the motorized vehicle (44 E-bike, 13 P-scooter), and in the remainder, it was a pedestrian. Only 11 injured riders (17.7\%) had worn a helmet at the time of the accident, of whom 6 were riding $\mathrm{P}$-scooters (45.5\% of all P-scooter riders). The difference in the rate of helmet use by type of vehicle was statistically significant $(p=0.045$, OR $=0.257)$.

\section{Presentation at the ED}

Of the 62 patients with oral and maxillofacial injuries, $40(64.5 \%)$ presented to the ED in the day hours and 22 (35.5\%) at the night hours. None of the 22 riders who presented at night wore a helmet compared to $27.5 \%$ of 40 riders who presented during the day $(p=0.005)$.

\section{Diagnosis}

Sixty patients (96.8\%) scored 15 on the GCS at presentation and 2 scored 14. The distribution of cases by imaging modalities is shown in Fig. 3. Diagnostic imaging was not required in 14 patients $(22.6 \%)$, and plain radiographs sufficed in 20 (32.3\%). All 62 patients were found

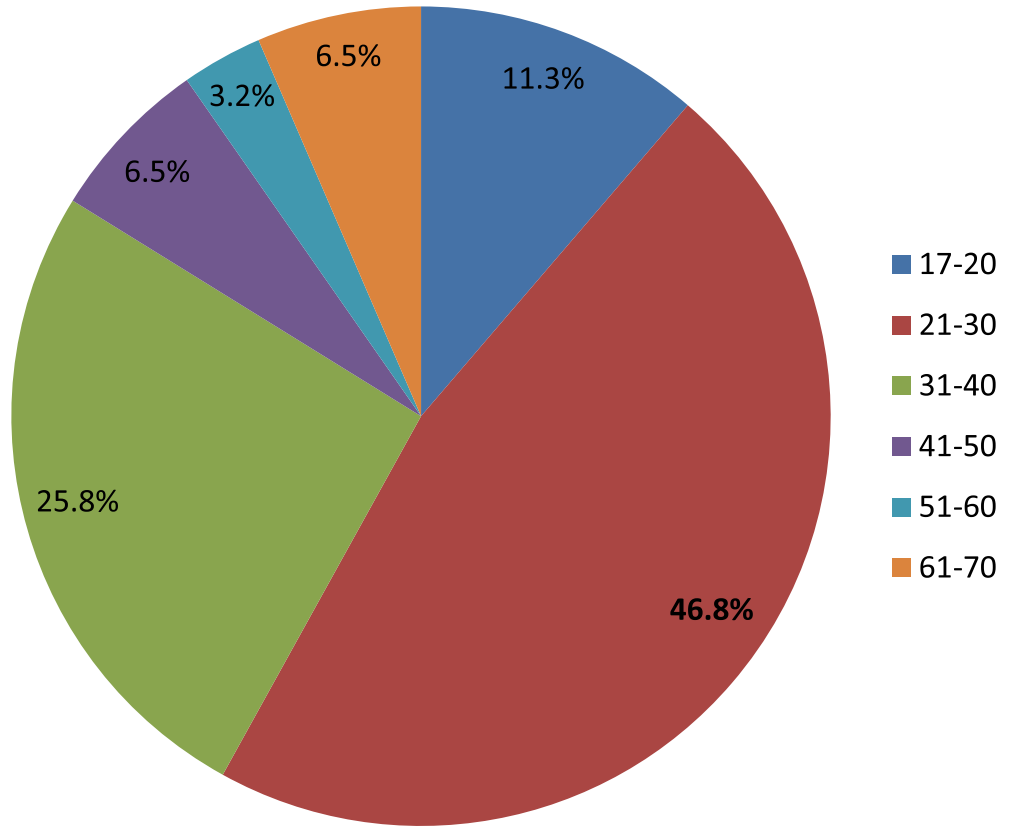

Fig. 1 Distribution of E-bike- and P-scooter-associated oral and maxillofacial injuries by age 


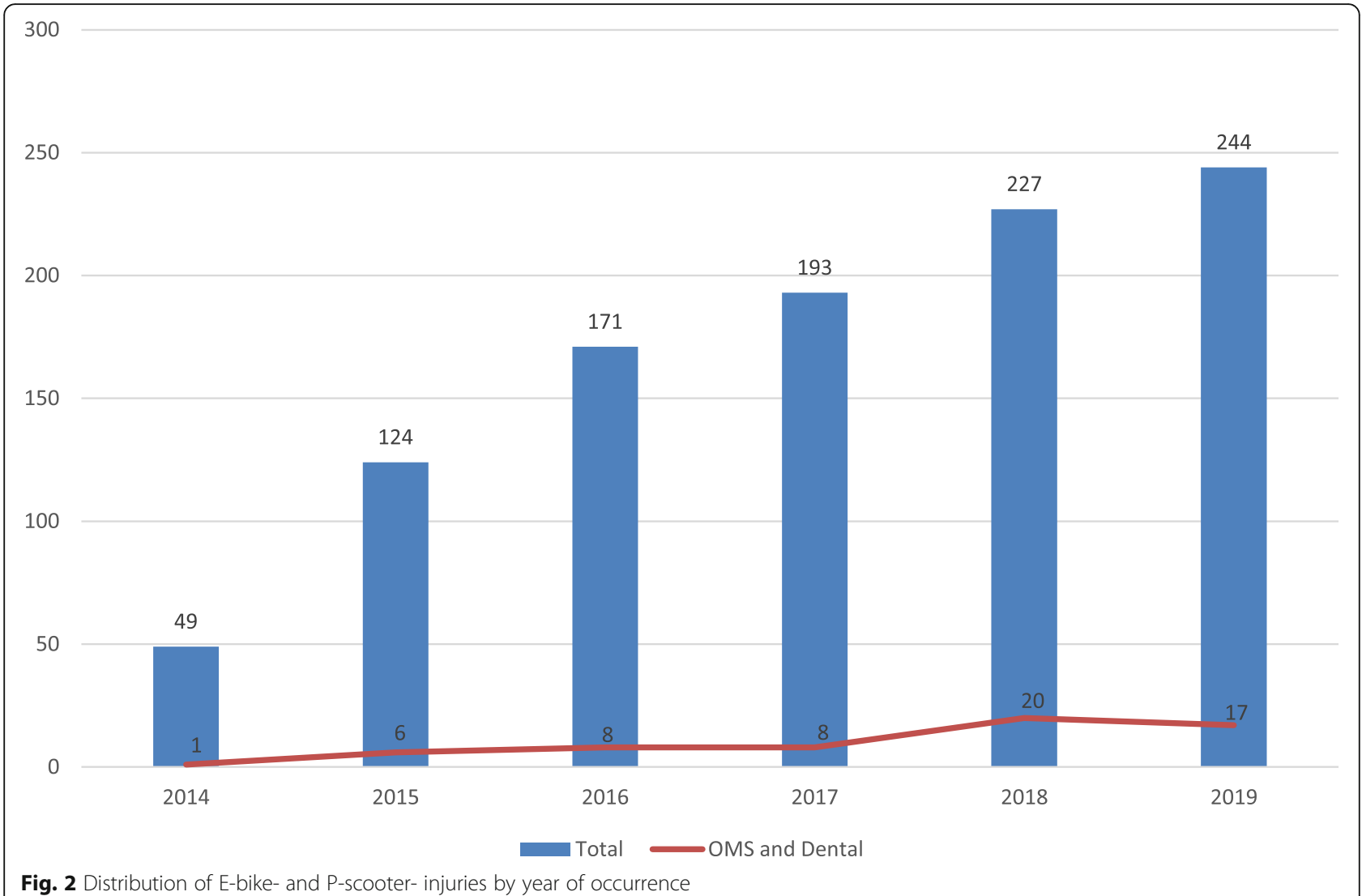

Fig. 2 Distribution of E-bike- and P-scooter- injuries by year of occurrence

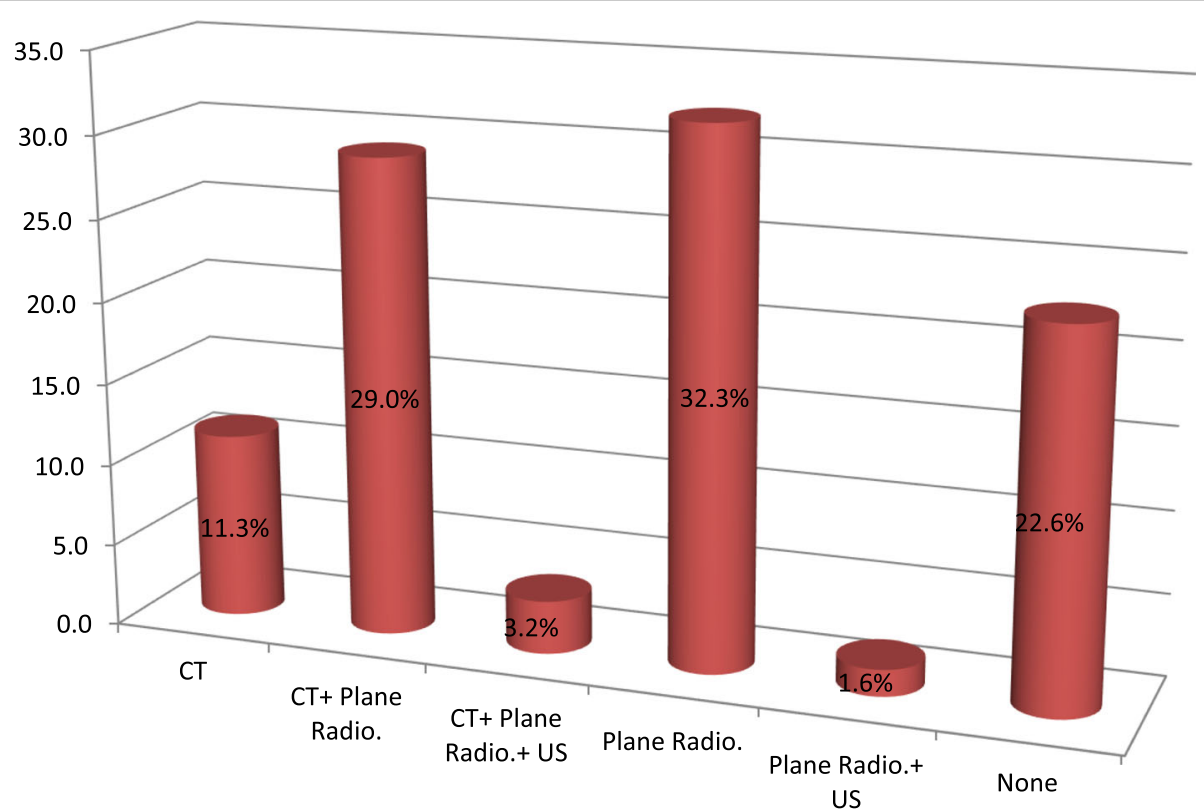

Fig. 3 Distribution of imaging modalities used for diagnosis of E-bike- and P-scooter oral and maxillofacial injuries 
to have hard- and soft-tissue facial injuries; 20 (32.3\%) had head injuries and 22 (35.5\%), dentoalveolar injuries.

\section{Head injury}

Forty-three patients (69.4\%) presented during the week, and 40 patients (64.5\%) self-evacuated. Head injury, diagnosed in 20 riders, was significantly associated with ED presentation on the weekend $(n=11$, $57.9 \%)$ rather than during the week $(n=9 ; 20.9 \%)$ $(p=0.004)$ and occurred more often in riders who did not wear a helmet $(37.3 \%)$ than in those who did $(9.1 \%)$, although the difference was not statically significance $(p=0.07)$.

\section{Hard- and soft-tissue injuries}

All 62 patients had hard- and soft-tissue injuries, 58 $(93.5 \%)$ bilaterally. Injuries were limited to the left side in $4.6 \%$ of patients and the lower right side in $1.6 \%$. Organs/areas sustaining injury included the face (all patients), thorax, back, abdomen and pelvis, upper extremities (54.8\%), and lower extremities (29.0\%). The risk of bilateral injuries was significantly higher in riders who were not wearing a helmet than in riders who were (96.1\% vs $81.8 \%, p=0.07, \mathrm{OR}=0.184$ ).

Skeletal injuries were documented in 18 patients (29\%), including $12(66.7 \%)$ with closed fractures. One bone was fractured in 13 patients $(72.2 \%)$ and more than one (up to 5 ) in 5 (27.8\%). The maxilla was injured most often, in 6 patients $(33.4 \%)$, followed by the radius in 5 patients $(27.8 \%)$. The distribution of hard-tissue trauma is shown in Table 1. The mean number of bones fractured in patients presenting at night ( $12 \mathrm{pm}$ to $6 \mathrm{am}$ ) was twice that in patients presenting in the morning (6 am to $12 \mathrm{am})$; ( 0.78 vs $0.38, p=0.61$, Kruskal Wallis test. E-bikes were involved in a mean of 0.52 bone fractures compared to 0.29 for P-scooters $(p=0.48$, MannWhitney test). Rates of skeletal injury sustained by riders wearing/not wearing helmets were 18.2 and $31.2 \%$, respectively $(p=0.094)$.

Lacerations were found in 37 patients (59.7\%), mostly of the lips, in 18 patients (48.7\%), and chin, in 8 patients (21.6\%). The distribution of soft tissue trauma is shown in Table 1. Ten riders who wore helmets $(90.9 \%)$ had lacerations compared to $27(52.9 \%)$ who did not $(p=$ 0.02, OR 8.9).

\section{Dentoalveolar injury}

Dentoalveolar injury was not examined in 40 cases (64.5\%). Among the remainder, 20 patients (47.6\%) had tooth fractures (crown and root) and $5(11.9 \%)$ had subluxation. Other injuries included alveolar process trauma $(n=1)$, tooth avulsion $(n=3)$, and prosthetic restoration fracture or loss $(n=2)$ (Table 1$)$. In 10 cases $(45.5 \%)$, one tooth was involved, and in 6 (27.3\%), two teeth. E- bike accidents were responsible for a mean of 0.75 tooth fractures in riders and 0.2 in pedestrians $(p=0.49)$. The mean number of teeth fractured was higher in E-bikerelated injuries than P-scooter-related injuries ( 0.83 vs $0.29, p=0.21)$. Dentoalveolar injury was less common in riders who word helmets than in riders who did not (23.7\% vs $37.3 \%, p=0.53)$.

\section{Treatment and outcome}

Bleeding, identified in 8 patients (12.9\%, including $4.8 \%$ subdural, $4.8 \%$ epistaxis, and $1.6 \%$ involving both lips and chin), was managed by local homeostasis agents and instruments. In no case was a transfusion required.

Seven patients were referred for surgery performed in the operating room under general anaesthesia in the following departments: oral and maxillofacial surgery (3.2\%), neurosurgery (3.2\%), orthopedics $(3.2 \%)$, and ophthalmology (1.6\%) (Fig. 4). Two operations were performed under general anesthesia. Three patients each (4.8\%) were admitted for 1-2 days and 1 (1.6\%) was admitted for 3 days. None required intensive care unit treatment. The remaining 55 patients $(88.7 \%)$ were discharged home from the ED on the same day. One patient was referred for rehabilitation. Repeated visits to the ED for the same complaint were documented in 7 cases (11.3\%).

Most dentoalveolar injuries (80.6\%) did not require treatment. Stitching was performed in 6 cases $(9.7 \%)$, open reduction and internal fixation in 2 , tooth fixation in 2 , and mandibulo-maxillary fixation or extraction in 1 patient each (Table 2).

\section{Discussion}

The rising popularity of E-bikes and P-scooters has resulted in a proportional increase in related injuries $[1,2,4]$. Although the prevalence of oral and maxillofacial injuries associated with these motorized vehicles appears to be rising $[1,2]$, the rate in our study (62 of 1417 patients, 4.4\%) was nevertheless considerably lower than the $10.3 \%$ reported in the recent, similarly designed, study of Lin et al. [1]. The difference may be attributable to the low rates of alcohol use $(6.5 \%)$ and drug use $(0 \%)$ by our patients, both known risk factors in head and maxillofacial injuries $[1,2,5]$.

We found that injuries involving E-bikes were more severe than injuries involving P-scooters, in agreement with the study of DiMaggio et al. [2]. The mean number of bones and teeth fractured in E-bike accidents was double and triple, respectively, the number fractured in P-scooter accidents. This is probably explained by the significantly better self-protection of the P-scooter riders, among whom nearly half wore a helmet compared to only $17.8 \%$ of the E-bike riders $(p=0.045)$. Israeli law stipulates that $\mathrm{P}$-scooter riders aged more than 16 years must wear a helmet only on intercity routes. 
Table 1 Distribution of oral and maxillofacial injuries associated with E-bikes and P-scooters in 62 patients

\begin{tabular}{|c|c|}
\hline Injuries & $\begin{array}{l}\text { No of patients } \\
(\%)\end{array}$ \\
\hline \multicolumn{2}{|l|}{ Hard-tissue injuries/fractures } \\
\hline Number of fractures & $18(29 \%)$ \\
\hline Maxilla & $3(4.8)$ \\
\hline Mandible & $2(3.2)$ \\
\hline Orbit & $2(3.2)$ \\
\hline Radius & $2(3.2)$ \\
\hline Fingers & $2(3.2)$ \\
\hline Temporal bone & $1(1.6)$ \\
\hline Maxilla + nasal bone + orbit + zygoma & $1(1.6)$ \\
\hline Maxilla + orbit + zygoma + pterygoid + tibia & $1(1.6)$ \\
\hline Radius + maxilla & $1(1.6)$ \\
\hline Nasal bone & $1(1.6)$ \\
\hline Radius + nasal bone + mandible & $1(1.6)$ \\
\hline Radius + zygoma & $1(1.6)$ \\
\hline \multicolumn{2}{|l|}{ Soft-tissue injuries/lacerations } \\
\hline Number of lacerations & $37(59.7 \%)$ \\
\hline Lips & $11(17.7)$ \\
\hline Cheek & $4(6.5)$ \\
\hline Chin & $3(4.8)$ \\
\hline Chin + lips & $3(4.8)$ \\
\hline Intra oral & $3(4.8)$ \\
\hline Lips + nose & $2(3.2)$ \\
\hline Eyebrows & $2(3.2)$ \\
\hline Upper extremities & $2(3.2)$ \\
\hline Eyelids & $1(1.6)$ \\
\hline Chin + eyelids & $1(1.6)$ \\
\hline Chin + lips + nose & $1(1.6)$ \\
\hline Lips + intra oral & $1(1.6)$ \\
\hline Nose & $1(1.6)$ \\
\hline Nose + intra oral & $1(1.6)$ \\
\hline Eyebrows + head & $1(1.6)$ \\
\hline \multicolumn{2}{|l|}{ Dentoalveolar injury } \\
\hline Number of dentoalveolar injuries & $22(35.5)$ \\
\hline Tooth fracture & $13(21.0)$ \\
\hline Tooth fracture + subluxation & $3(4.8)$ \\
\hline Avulsion + tooth fracture & $2(3.2)$ \\
\hline $\begin{array}{l}\text { Avulsion + tooth fracture }+ \text { alveolar process } \\
\text { fracture }\end{array}$ & $1(1.6)$ \\
\hline $\begin{array}{l}\text { Tooth fracture + subluxation + dental restoration } \\
\text { damage }\end{array}$ & $1(1.6)$ \\
\hline Subluxation & $1(1.6)$ \\
\hline Dental restoration damage & $1(1.6)$ \\
\hline
\end{tabular}

For E-bikes, riders aged less than 18 years must wear helmets at all times, and riders aged 18 years or more must wear helmets only on intercity routes. In our study, the average age of the total patients injured in E-bike/Pscooter accidents was $31.6 \pm 15.8$ years, and the majority of those with oral and maxillofacial injuries were aged 21-30 years. Thus, we suggest that more stringent requirements for riders $\geq 18$ years old should be considered.

Although Lin et al. [1] reported that almost half the Ebike and P-scooter accidents involving oral and maxillofacial injuries occurred during the day, riders in our study appeared to be less careful during night hours, when none wore a helmet compared to $27.5 \%$ during day $(p=0.005)$. Accordingly, the mean number of fractured bones in night-time accidents was double the number in daytime accidents $(p=0.61)$. Among all riders, there were no fractured bones in $81.8 \%$ of those wearing a helmet but only $68.8 \%$ of those who were not $(p=0.094)$. Thus, wearing a helmet appears to be associated with a decreased risk of bone fractures.

A previous study examining orthopedic injuries associated with E- scooters found that bones of the upper and lower extremities were most likely to be fractured ( 43.8 and $57.5 \%$ of patients, respectively) [4]. These values are in line with our study wherein $54.8 \%$ of patients with oral and maxillofacial injuries had upper-extremity fractures and $29.0 \%$ had lowerextremity fractures. The most common fractured bones were the maxilla (33.4\%) and radius (27.8\%). Given that our cohort was limited to patients who sustained oral and maxillofacial injuries, we assume that we were more likely to find upper-extremity injuries, which are closer to the face, than lowerextremity injuries.

Although, as in our study, Lin et al. [1] found the maxilla to be the most common facial bone fractured, they also reported zygomatic bone injury in $48.28 \%$ of pedestrians with oral and maxillofacial injuries. Thus, in patients with E-bike- and P-scooter-related trauma, skeletal injuries may be found primarily in the zygomatic maxillary complex.

E-bikes and P-scooters can also cause soft-tissue injuries. We found that soft-tissue lacerations were the most common injury (59.7\%), and the lips were the most common site affected. Similar results were reported by Badeau et al. [6] in a study of general ED visits for Escooter-related injuries. Surprisingly, riders who wore a helmet had a significantly higher probability of softtissue lacerations than riders who did not $(90.9 \%$ vs $52.9 \% ; p=0.02$, $\mathrm{OR}=8.9$ ). This finding may be related to an earlier prospective cross-sectional study of the relationship of soft-tissue injuries with helmet use in motorcycle accidents [7] in which riders wearing full-face 


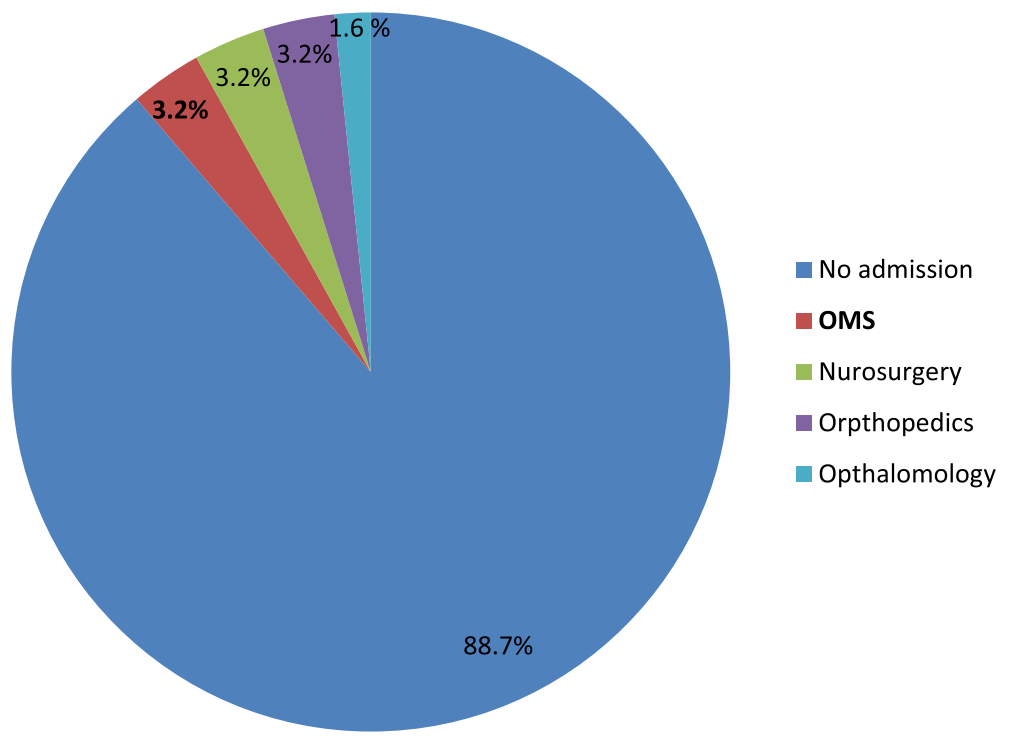

Fig. 4 Distribution of departmental referrals of patients presenting to the ED with E-bike- and P-scooter-associated oral and maxillofacial injuries

helmets had an increased incidence of mid-face injuries [7]. The authors suggested that these injuries were the result of breakage of the plastic helmet visor on impact [7]. In the present study, only dichotomic information on helmet use was available (use/non-use). We plan to conduct future studies comparing types of helmets in this context.

Dentoalveolar injury was documented in $35.5 \%$ of our patients. Lin et al. [1] found that only $24.8 \%$ of oral and maxillofacial injuries involved teeth, alveolar bone, and gingiva. However, they reported only on cases that led to hospitalization and were more severe than the injuries seen in our patients, most of which were tooth fractures $(47.6 \%)$ and were classified as mild (i.e., requiring no treatment or suturing). Dentoalveolar injury was less common in riders who wore helmets $(23.7 \%)$ than in riders who did not (37.3\%).

Overall, the injuries sustained by our cohort were mild to moderate. Most of the patients self-evacuated, and almost all (96.8\%) had a GCS of 15 at presentation. Only $32.3 \%$ had head injury, which was found to be related to

Table 2 Distribution of treatment modalities for oral and maxillofacial injuries in 62 patients

\begin{tabular}{ll}
\hline Treatment modalities & No of cases (\%) \\
\hline No treatment & $45(72.6)$ \\
Suturing & $12(19.4)$ \\
ORIF & $2(3.2)$ \\
Closed reduction & $1(1.6)$ \\
Oculoplastic surgery & $1(1.6)$ \\
Orthopedic surgery & $1(1.6)$ \\
\hline
\end{tabular}

OMS Oral and maxillofacial surgery, ORIF Open reduction and internal fixation weekend (as opposed to weekday) accidents $(p=0.004)$ and lack of helmet protection $(p=0.07)$. These findings are in line with a previous study on general ED referrals for E-scooter-related injuries [6], wherein $24 \%$ of patients were evacuated by ambulance and only $16 \%$ required hospitalization [6]. Trivedi et al. [5] reported a relatively higher rate of severe E-bike-related injuries (58\%) among all admissions for injuries of the craniofacial complex. However, none of the riders was wearing a helmet and $18 \%$ reported alcohol use.

The major limitation of the study may be probably that data collection was retrospective, and information regarding type of helmet that was used (full face, half face, modular, half shell, etc.) were missing. Future researchers should be design as prospective and include varies data as desired, including helmet type, which has a major impact on the type and severity of E-bikes and P-scooters related injuries. Moreover, including a larger number of patients involved with oral and maxillofacial injuries can improve results significance. This can be done by combining several medical centers in the country or in several countries for inclusive longitudinal studies.

\section{Conclusion}

In summary, we evaluated the number and severity of oral and maxillofacial injuries associated with E-bikes and P-scooters and the impact of helmet use. The rising incidence of oral and maxillofacial injuries can be attributed to the rapid dissemination and widespread use of E-bikes and P-scooters together with poor awareness of the value of protective equipment on injury severity. This study showed that helmet use seems to decrease 
the probability of head injury and the number of hard tissue and dentoalveolar injuries. Paradoxically, wearing a helmet was associated with an increased occurrence of soft-tissue injuries. These results may provide some guidance towards the formulation of effective safety legislation and improved treatment programs.

\section{Abbreviations}

E-bikes: Electric-powered bikes; P-scooters: Powered scooters; ED: Emergency department

\section{Acknowledgements}

N/A

\section{Authors' contributions}

Y.H. Data collection, data analyses, literature review, and drafting the manuscript. D.B.H. Data collection. N.C. Advising. M.J.D. Advising. G.C. Designing the study and the principal investigator. B.H.Y. Data analyses, literature review, and drafting the manuscript. All authors read and approved the final manuscript.

\section{Funding}

No funding was received for this study.

\section{Availability of data and materials}

The datasets used and/or analyzed during the current study are available from the corresponding author on reasonable request.

\section{Declarations}

\section{Ethics approval and consent to participate}

The study protocol was approved by the Helsinki Committee of Rabin Medical Center (approval number 0194-20-RMC).

\section{Consent for publication}

$\mathrm{N} / \mathrm{A}$.

\section{Competing interests}

The authors declare that they have no competing interests.

\section{Author details}

'Department of Oral and Maxillofacial Surgery, Rabin Medical Center Beilinson Hospital, 4941492 Petach Tikva, Israel. ${ }^{2}$ Department of Orthopedic Surgery, Rabin Medical Center - Beilinson Hospital, Petach Tikva, Israel. ${ }^{3}$ Sackler School of Medicine, Tel Aviv University, Tel Aviv, Israel. ${ }^{4}$ Department of Emergency Medicine, Rabin Medical Center - Beilinson Hospital, Petach Tikva, Israel. ${ }^{5}$ The Maurice and Gabriela Goldschleger School of Dental Medicine, Tel Aviv University, Tel Aviv, Israel. ${ }^{6}$ Oral and Maxillofacial Private Clinic, Herzliya, Israel.

\section{Received: 26 January 2021 Accepted: 23 August 2021}

Published online: 01 September 2021

\section{References}

1. Lin S, Goldman S, Peleg K, Levin L. With support of the Israel Trauma Group. Dental and maxillofacial injuries associated with electric-powered bikes and scooters in Israel: a report for 2014-2019. Dent Traumatol. 2020;36:533-7.

2. DiMaggio CJ, Bukur M, Wall SP, Frangos SG, Wen AY. Injuries associated with electric-powered bikes and scooters: analysis of US consumer product data. Inj Prev. 2019;26:524-8.

3. Gojanovic B, Welker J, Iglesias K, Daucourt C, Gremion G. Electric bicycles as a new active transportation modality to promote health. Med Sci Sports Exerc. 2011;43:2204-10

4. Ishmael CR, Hsiue PP, Zoller SD, Wang P, Hori KR, Gatto JD, et al. An early look at operative orthopaedic injuries associated with electric scooter accidents: bringing high-energy trauma to a wider audience. J Bone Joint Surg Am. 2020;102:e18.

5. Trivedi B, Kesterke MJ, Bhattacharjee R, Weber W, Mynar K, Reddy LV. Craniofacial injuries seen with the introduction of bicycle-share electric scooters in an urban setting. J Oral Maxillofac Surg. 2019;77:2292-7.
6. Badeau A, Carman C, Newman M, Steenblik J, Carlson M, Madsen T. Emergency department visits for electric scooter-related injuries after introduction of an urban rental program. Am J Emerg Med. 2019;37:1531-3.

7. Arif MZ, Rajanikanth BR, Prasad K. Soft tissue injuries of the maxillofacial region occurring from motorcycle accidents. J Maxillofac Oral Surg. 2019;18: 432-9.

\section{Publisher's Note}

Springer Nature remains neutral with regard to jurisdictional claims in published maps and institutional affiliations.

\section{Ready to submit your research? Choose BMC and benefit from:}

- fast, convenient online submission

- thorough peer review by experienced researchers in your field

- rapid publication on acceptance

- support for research data, including large and complex data types

- gold Open Access which fosters wider collaboration and increased citations

- maximum visibility for your research: over $100 \mathrm{M}$ website views per year

At $\mathrm{BMC}$, research is always in progress.

Learn more biomedcentral.com/submissions 